\title{
In vitro antioxidant activity of methanolic extracts of Ageratum conyzoides and Ageratina adenophora leaves
}

\author{
P. Khazeo, Muslek Uddin Mazumder, K. Nusalu Puro, Rosamund Jyrwa, Nungshioba Jamir, \\ Lalzikpuii Sailo*
}

Department of Pharmacy, Regional Institute of Paramedical and Nursing Sciences, Zemabawk 796017, Mizoram, India

Corresponding author: zikpuii08@gmail.com

\begin{abstract}
Characterization of natural products based on the antioxidant activity gains tremendous interest in the past decade. In the current work, the antioxidant activity of the methanolic extract of Ageratina adenophora and Ageratum conyzoides leaves were determined. Both plants belong to the family Asteraceae and are invasive species in many tropical and subtropical countries, including northeastern India, China, Sri lanka, Nigeria. A. conyzoides is an annual herbaceous plant having a number of bioactive compounds. A. conyzoides is typically found in cultivated fields and other disturbed ecosystems; and is known for its medicinal use in the treatment of burns and wounds, arthritis, asthma, dermatitis, leprosy, malaria, and as an insecticide. Notable compounds include toxic pyrrolizidine alkaloids, phenolic acids, cumarin and polymethoxyflavones. In this study, antioxidant activity of the plant leaves was characterized for DPPH (2, 2-diphenyl-1-picrylhydrazy) and hydrogen peroxide radical scavenging activity. Antioxidant activity determines the potential of a compound to scavenge a free radical generated during oxidative stress in the body. The result suggests that $A$. adenophora and A. conyzoides leaves extracts showed potential antioxidant activity in terms of both DPPH and hydrogen peroxide scavenging activity.
\end{abstract}

Keywords: Ageratina adenophora, Ageratum conyzoides, antioxidant activity, DPPH, hydrogen peroxide.

\section{INTRODUCTION}

India is culturally rich in species of herbal medicine, and there are more than 2000 of such plants in record. But very few plants have been studied for pharmacological and active chemical composition that are used in treatment of various health diseases (Dursum et al., 2004). Recent interest has been increased in oxygencontaining free radicals in biological systems as they are causative agents of a variety of chronic disorder. Therefore, there has been a focus on the protective biochemical function of naturally-occurring antioxidants containing (Larson, 1988).

Antioxidant are important substances that have ability to protect the body from cellular damages by free radical induced oxidative stress (Tomero et al., 2005). Free radicals on human beings are closely related to toxicity, diseases like chronic renal failure, diabetes mellitus, cancer, immune dysfunction and aging (Halliwell and Gutteridge, 1986; Maxwell, 1995). Studies have shown that antioxidant properties of plants prevent oxidative stress defense and are thus important remediation for different human diseases including cancer, atherosclerosis, and aging process (Stajner et al., 1998). The presence of antioxidants in Ageratum conyzoides has been reported (Neelabh et al., 2017). The plants which exhibit antioxidant activity were mostly the phytochemical which shown presence of phenols, terpenoids, and flavonoids (Krishnaiah et al., 2011; Kumar et al., 2013).

\section{Materials AND Method}

\section{Plant materials}

Fresh leaves of both Ageratina adenophora and Ageratum conyzoides were collected from in and around 
Zemabawk campus of Regional Institute of Paramedical and Nursing Sciences, Aizawl, Mizoram, India. The identity of the plant was authenticated by a taxonomist at the Botanical Survey of India, Shillong. A voucher specimen of these plants are deposited in the Department of Pharmacy, RIPANS with Reference no: BSI/ERC/TECH/ Plant Iden./2018/136

\section{Preparation of plant extracts}

The extraction of both plant metabolites were performed by procedure described in Dixit et al. (2005) with slight modification. The leaves were washed thoroughly with distilled water. Plant leaves were dried under shade until becomes completely dried and powdered coarsely by hand. The plant constituents are sequentially extracted using petroleum ether, chloroform, and methanol using the Soxhlet apparatus. The powdered leaves were extracted using each solvent to extract soluble matter. The extraction was continued until the extract solution became colorless. The extract was evaporated to dryness and store in refrigerator for the experiment.

\section{Hydrogen peroxide scavenging capacity}

The ability of $A$. adenophora and $A$. conyzoides methanolic extracts to scavenge hydrogen peroxide was determined with slightly modification to the method of Ruch et al. (1989). A solution of hydrogen peroxide (40 $\mathrm{mM}$ ) was prepared in phosphate buffer (pH 7.5). $1 \mathrm{ml}$ of the extract extract $(100 \mu \mathrm{g} / \mathrm{ml})$ in distilled water was added to hydrogen peroxide solution $(0.6 \mathrm{ml}, 40 \mathrm{mM})$. After 10 minute, absorbance was determined at $230 \mathrm{~nm}$ against a blank solution containing the phosphate buffer. The percentage of hydrogen peroxide scavenging were calculated by the formula (Keser et al., 2012):
$\%$ Scavenged $\left(\mathrm{H}_{2} \mathrm{O}_{2}\right)=(\mathrm{Ac}-\mathrm{As}) / \mathrm{Ac} \times 100$

Where Ac is the absorbance of the control and is the absorbance in the presence of the sample of the plant extract or standards.

\section{DPPH radical scavenging}

Sample stock solutions $(1.0 \mathrm{mg} / \mathrm{ml})$ were diluted to final concentrations of $20,40,60,80$, and $100 \mu \mathrm{g} / \mathrm{ml}$, in ethanol. $1 \mathrm{ml}$ of a $0.15 \mathrm{nM}$ DPPH ethanol solution was added to $2.5 \mathrm{ml}$ of sample solutions of different concentrations, and allowed to react at room temperature. Ethanol $(1.0 \mathrm{ml})$ plus plant extract solution $(2.5 \mathrm{ml})$ was used as a blank. DPPH solution $(1.0 \mathrm{ml} ; 0.15 \mathrm{mM})$ plus ethanol ( $2.5 \mathrm{ml}$ ) was used as a negative control. The positive controls were those using the standard solutions (Luciana et al., 2001). After $30 \mathrm{~min}$, the absorbance values were measured at $518 \mathrm{~nm}$ and converted into the percentage antioxidant activity using the following formula:

\section{Radical scavenging $(\%)=($ Ac-As $) / A c \times 100$}

Where Ac is the absorbance of the control, and As is the absorbance in the presence of the sample of the plant extracts or standards.

\section{RESULTS}

\section{DPPH radical scavenging activity}

Free radical scavenging activity in terms of DPPH for methanolic extract of A. conyzoides and A. adenophora

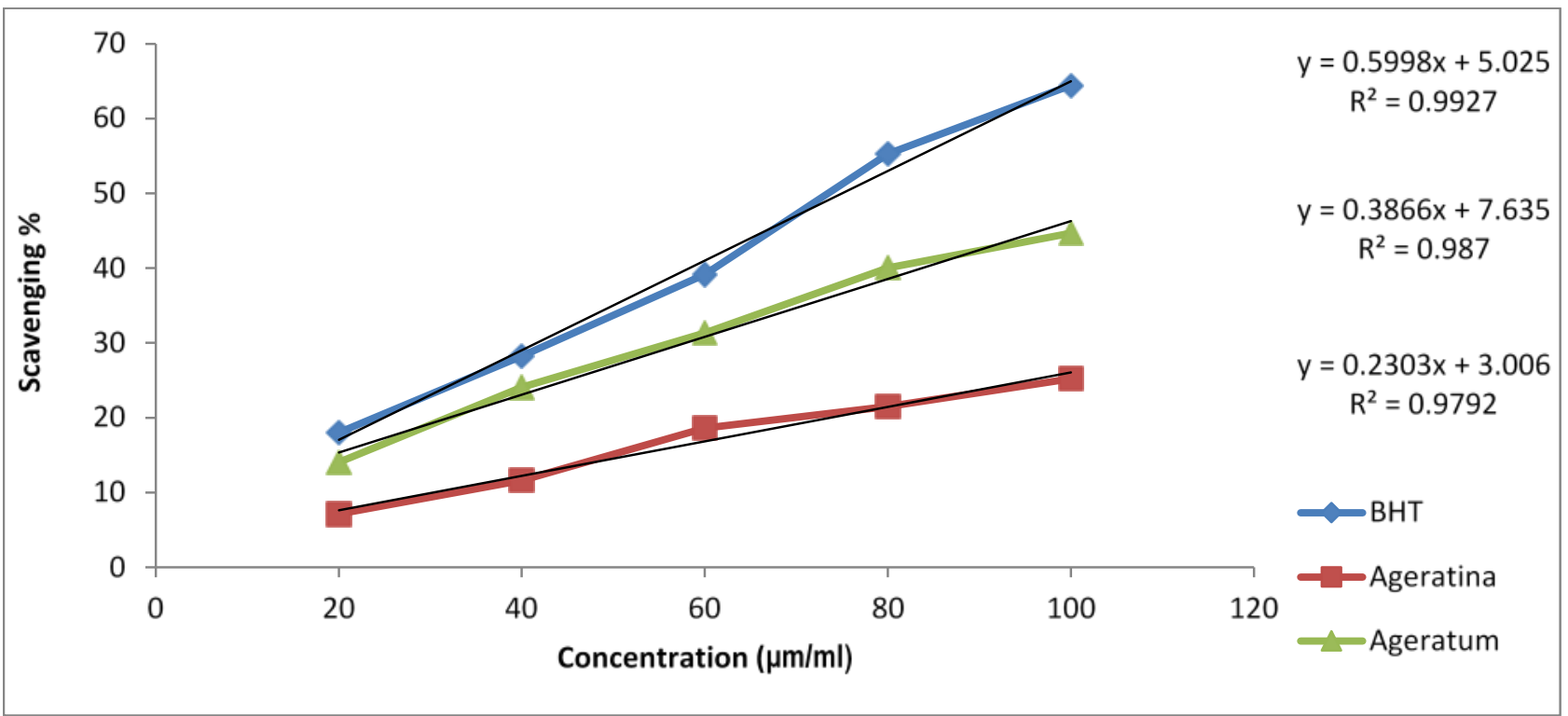

Figure 1: DPPH scavenging of A. conyzoides and A. adenophora with standard BHT. 
leaves were performed and the resulta are shown in Figure 1 . The $I \mathrm{I}_{50}$ values for plant extracts and standard butylated hydroxyl toluene (BHT) are shown in Table 1. BHT showed an $\mathrm{IC}_{50}$ of 68.043 , A. conyzoides leaves extract showed $\mathrm{IC}_{50}$ of 70.489 , and $\mathrm{A}$. adenophora leaves extract showed $\mathrm{IC}_{50}$ of 92.791 . Even though the leaves extract was not in pure formd it shows significant DPPH scavenging activity as compared to standard BHT. The antioxidant activity of the extract may be due to present phenol and other compound.

\section{$\mathrm{H}_{2} \mathrm{O}_{2}$ Scavenging capacity}

Table 1: $\mathrm{IC}_{50}$ value of methanolic plant extracts of $A$. adenophora and A. conyzoides with standard.

\begin{tabular}{|c|c|c|c|}
\hline Sl.no & Sample & Part & IC50 \\
\hline 1 & A. conyzoides & Leaves & 70.489 \\
\hline 2 & A. adenophora & Leaves & 92.791 \\
\hline 3 & BHT & Standard & 68.043 \\
\hline
\end{tabular}

The percentage scavenging capacity of methanol leaves extract $A$. conyzoides and $A$. adenophora with standard ascorbic acid are shown in the Table 2. The activity is lowest for A. conyzoides at $63.15 \%$, followed by A. adenophora at $79.32 \%$, and highest for ascorbic acid at $86.84 \%$ at $100 \mu \mathrm{g} / \mathrm{ml}$. From this we can conclude that the scavenging capacity of both plants are comparable to that of the standard. The scavenging capacity of A. adenophora is very close to that of ascorbic acid), so we can say that this plant extract has high antioxidant property. Therefore, both the plant extracts can be further studied for therapeutic and other utilities.

Table 2: $\mathrm{H}_{2} \mathrm{O}_{2}$ scavenging activity of A. adenophora and A. conyzoides with standard ascorbic acid.

\begin{tabular}{|c|c|c|c|}
\hline Sl.no. & Sample & $\begin{array}{c}\text { Concentration } \\
(\boldsymbol{\mu g} / \mathbf{m l})\end{array}$ & $\begin{array}{c}\text { \% scavenging } \\
\text { activity }\end{array}$ \\
\hline 1 & Control & 100 & \\
\hline 2 & A. conyzoides & 100 & 63.15 \\
\hline 3 & A. adenophora & 100 & 79.32 \\
\hline 4 & Ascorbic acid & 100 & 86.84 \\
\hline
\end{tabular}

\section{DISCUSSION}

From the study it was found that both A. adenophora and $A$. conyzoides possess antioxidant activity for the free radicals scavenging of DPPH and hydrogen peroxide. The antioxidant scavenges the free radicals generated in the body. The free radicals are mainly responsible for the oxidative stress in human body which lead to various diseases. The plant-based antioxidant can be utilized for various herbal formulations for mitigation and treatment because herbal formulations are cost effective as well as efficient. Thus, the antioxidant properties of these two plants can be utilized as an alternate source of treatment of various diseases (Choudhury et al., 2017).

\section{ACKNOWLEDGEMENT}

The author would like to acknowledge Dr. Chawngthanliana, Director, Regional Institute of Paramedical and Nursing Sciences, and Dr. H. Lalhlenmawia, Head of Department of Pharmacy, RIPANS, for providing facilities to conduct this research work. Authors also thank to Dr. A. A. Mao, Scientist-F \& Head of office, Botanical Survey of India (BSI), Shillong, for identification and authentication of plant species.

\section{REFERENCES}

Choudhury, N., Akhtar, N., Kumar, N. (2017.) Study on methanolic extract of Ageratum conyzoides for its ability to act as an antioxidant and to suppress microbial growth. The Pharma Innovation Journal 6(11), 170-173.

Dixit, P., Ghaskadbi, S., M ohan, H., Devasagayam, T.P.A. (2005). Antioxidant properties of germinated fenugreek seeds. Phytotherapy Research, 19(11), 977-983.

Dursum, E.S., Akcicek, E. (2004). Herbs as food source in Turkey. Asian Pacific J. Cancer Prev. 5, 722-733.

Halliwell, B., Gutteridge, J.M. (1986). Oxygen free radicals and iron in relation to biology and medicine: some problems and concepts. Archives of Biochemistry and Biophysics. 246(2), 501-514.

Krishnaiah, D., Sarbatly, R., Nithyanandam, R. (2011). A review of the antioxidant potential of medicinal plant species. Food and Bioproducts Processing. 89(3), 217233.

Kumar, N., Kale, R.K., Tiku, A.B. (2013). Chemopreventive effect of Lagenaria in two stages DM BA plus carton oil-induce skin papillomagenesis. J. Nutrition and Cancer. 65(7), 991-1001.

Larson, R.A. (1988). The antioxidants of higher plants. Phytochemistry 27, 969-978.

Mensor, L.L., Menezes, F.S., Leitão, G.G., Reis, A.S., Santos, T.C., Coube, C.S., Leitão, S.G. (2001). Screening of Brazilian plant extracts for antioxidant activity by the use of DPPH free radical method. Phytotherapy Research. 15(2), 127-130.

Maxwell, S.J. (1995). Prospects for the use of antioxidant therapies. Drugs. 49, 345.

Romero, A., Saavedar, R.G. (2005). Screening Bolivian plants for antioxidant activity. Pharmaceutical Biol. $45,79-86$.

Ruch, R.J., Cheng, S.J., Klaunig, J. E. (1989). Prevention of cytotoxicity and inhibition of intracellular communication by antioxidant catechins isolated from Chinese green tea. Carcinogenesis, 10, 1003-1008. 
Stajner, D., Milic, N., Mimica-Dukic, N., Laziclgic, R. (1998). Antioxidant abilities of cultivated and whild species of garlic. Phytother. Res. 12, S13-S14.
Keser, S., Celik, S., Turkoglu, S., Yilmaz, O., Turkoglu, I. (2012). Hydrogen peroxide radical scavenging and total antioxidant activity of hawthorn. Chem J. 2(1), 912 